The concepts of auctoritas and potestas in the Modern epoch

\title{
Los conceptos de auctoritas y potestas durante la época moderna
}

\author{
José Morales Fabero
}

UNED

jmoralesf@hotmail.es

DOI: https://doi.org/10.15366/bp.2020.24.017

Bajo Palabra. II Época. No 24. Pgs: 337-358

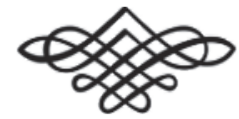


Recibido: 20/09/2018

Aprobado: 12/08/2020

\section{Resumen}

Los vocablos auctoritas y potestas, provienen del Derecho Romano y constituyeron la piedra angular sobre la que se asentaba el funcionamiento de la $c i$ vitas. La transmisión y proyección hacia el porvenir de este aspecto de la tradición romana dará lugar a la conformación de una serie de hábitos de diversa índole denominados inores maiorum. Tradición en la que la potestas se define como una fuerza que emana de la legitimidad otorgada por la sociedad civil y la auctoritas como la distinción de determinadas personas basada en una serie de características morales e intelectuales que las destacan del resto. Este constructo arquetípico parece desmoronarse con la llegada de la época moderna, debido a que la misma parece romper con la tradición y los prejuicios.

Palabras clave: auctoritas, potestas, época moderna, legitimación del poder.

\section{Abstract}

The words auctoritas and potestas come from the Roman law and they constituted the angular stone on which the functioning of the civitas was settling itself. The transmission and projection towards the future of this incipient Roman ethos will shape an array of social, juridical and religious habits that we know with the name of inores maiorum. The potestas like a force delegated by the beast publishes and the auctoritas rather as a prerogative of certain subjects based on the charisma and on the personal prestige; a public ethics that guide will recognize the community as Superior. This archetypal constructo seems to crumble with the arrival of the modern epoch, due to the fact that the same one seems to break with the tradition and the prejudices.

Keywords: auctoritas, potestas, modern epoch, legitimization of the power. 


\section{Introducción}

Partimos de la aceptación de que el hombre es un ser eminentemente social ${ }^{1}$, por ello forma con sus semejantes comunidades más o menos complejas que le permiten satisfacer sus necesidades, solucionar sus problemas e interaccionar con el entorno natural y otros grupos humanos. Cualquier organización social está organizada, en mayor o menor medida, por el poder $^{2}$.

El término poder proviene del verbo latino «possum -potes -potuī,-posse», que en su acepción más lata y general significaba ser capaz, tener fuerza para algo, ser potente, ya fuese que tal potencia se aplicara a lograr el dominio o posesión de un objeto físico o concreto, o al desarrollo de una actividad de índole moral, política o científica. Con esta acepción se relaciona con el concepto "potestas» (potestad, potencia, poderío), utilizado como equivalente a «facultas» (posibilidad, capacidad, virtud, talento). Enlazados íntimamente con la idea del poder "[...] se hallan los conceptos de «imperium» (el mando supremo de la autoridad), de «arbitrium» (la voluntad o el albedrío propios ejercidos en el uso del poder), de potentia (la fuerza, poderío o eficacia de alguien), y de «auctoritas» (la autoridad o influencia moral que emanaba de su virtud)"3.

Los vocablos «auctoritas y potestas» -procedentes del Derecho Romano clásico- que han evolucionado etimológicamente desde su significado original ${ }^{4}$. A este respecto, Revault d'Allonnes, basándose en Hannah Arendt ${ }^{5}$, recuerda el esfuerzo de los romanos por perpetuar lo público inscribiéndolo en una duración indeterminada, para que no dependa de las variaciones políticas o institucionales. Esta

\footnotetext{
${ }^{1}$ Aristóteles "Política”, Traducción y notas de Manuela García Valdés. Ed. Gredos, Madrid 2007. libro 1, pág.4647.

2 Del lat.vulg. *potère, creado sobre ciertas formas del verbo lat. posse'poder', como potes 'puedes', poteram 'podía' potuisti 'pudiste“... etc. Diccionario de la Real Academia Española, Ed. XXI, Madrid 1992. Pág. 1629.

3 Mayz-Vallenilla, Ernesto. “El dominio de poder”. Ed. De la Universidad de Puerto Rico, 2a ed. 1999. Págs. 8-9

${ }^{4}$ El primer tipo de organización político-social que conocerá el asentamiento protorromano será el gentilicio. El protagonismo corresponderá en esta organización pre-cívica a las gentes. Posteriormente, tendrá lugar un proceso de disolución de la organización gentilicia y el tránsito a la civitas (= universitas civium'), de modo similar a la polis griega, momento incipiente de muchas de las instituciones romanas y también de la idea de auctoritas. La transmisión y proyección hacia el porvenir de este incipiente ethos romano conformará un acervo de hábitos sociales, jurídicos y religiosos que conocemos con el nombre de inores maiorum. Cfr. F. Javier Casino Mora (1999). "El dualismo autoridad-potestad como fundamento de la organización y del pensamiento políticos de Roma". Polis. Revista de ideas y formas politicas de la Antigüedad Clásica II, pp. 85-109.

5 Cfr. Arendt, H. (1996) “¿Qué es la autoridad? En: Entre el pasado y el futuro”. Barcelona: Península.
} 
autora sostiene que «el tiempo tiene fuerza de autoridad» ${ }^{6}$, ya que la tradición, en el sentido de lo que ha funcionado con anterioridad, tiene un valor, asignándole a la distinción entre la potestas y la auctoritas el acto fundacional de la civitas romana:

«[...]. Así pues, el interés por la posteridad es indisoluble del interés por la anterioridad. No se trata solo de perpetuar lo que siempre ha sido, sino asentar el cambio sobre el continuum temporal [...] La auctoritas se despliega siempre en el tiempo, se sitúa simultáneamente hacia atrás, como fuerza de proposición, y hacia adelante, como elemento de ratificación o de validación.» ${ }^{7}$

Por tanto, las normas que se van configurando conforme progresa la sociedad, nacen en el interior de la propia comunidad y no vienen marcadas por la política. Será en el contexto de esa vida política donde surgirán y se desarrollarán los términos de potestas y auctoritas. La principal diferencia entre ambos términos es que la autoridad se relaciona más bien con el concepto de guía, de un ser humano que por sus cualidades y virtudes destaca y el resto lo considera como una especie de guía espiritual, mientras que la potestad surge cuando el poder es establecido por los propios seres humanos con el fin de jerarquizar y conducir una determinada sociedad; poder que no se define por las cualidades sino por la fuerza y el liderazgo. Por tanto, la «auctoritas» aparece como una cosa que trasciende al ciudadano u hombre común, siendo un factor de ordenación social incontestable y previa, que está por encima de las lides humanas y de las vicisitudes, que se vincula a la religión ${ }^{8}$.

Ambos términos -«auctoritas y potestas»- se hallan estrechamente vinculados y la relación puede concretarse en el tiempo y el espacio. Su aparición más cercana se encuentra en el marco de la constitución política romana, como venimos apuntando, donde destaca el concepto de «auctoritas». Este concepto se trata de un "caracterismo genuinamente romano" ", que podemos admirar en su mayor plasticidad en la formula «Senatus Populusque Romanus» (el Senado y el pueblo de Roma) es decir, la llamada constitución mixta republicana, basada en una genial interrelación entre la autoridad del Senado («auctoritas patrum») y la «maiestas Populi», que se concretaba en la "potestas» de los magistrados (imperium en el caso de "collegae maiores»).

Por ello, en un primer momento, el término «auctoritas» se contrapone al de poder o «potestas» en su esencia, pero a su vez ambos se complementan, lo que ha dado lugar al binomio o dualismo «auctoritas-potestas», que caracterizó la teoría política

\footnotetext{
${ }^{6}$ Revault d'Allonnes, M. (2006), Le pouvoir des commencements. Essai sur l'autorité. Éditions du Seuil. Traducción de Estela Consigli: El poder de los comienzos, Buenos Aires, Amorrortu, 2008, pág. 35.

7 Ibid. Págs. 30-35.

${ }^{8}$ Royo Arpón, J. Ma. "Palabras con poder”. Ed. Marcial Pons Madrid, 199. Págs. 38 y ss

9 Ver D'Ors, A., Autoridad y potestad en "Escritos varios sobre el derecho en crisis", C.S.I.C, Roma- Madrid 1973, pp. 93-104.
} 
durante la época romana e influyó en gran medida en etapas posteriores, hasta la actualidad, si bien con una considerable y progresiva mutación de los términos ${ }^{10}$. Por tanto, es indudable que ambos términos estaban emparentados en el derecho romano, donde la «auctoritas» es la cualidad a través de la que ciertas personas se ganaban el respeto y la admiración del resto gracias a sus virtudes, sus valores como ser humano y su experiencia. Por lo tanto, el hecho de poseer «potestas» no implicaba poseer «auctoritas» $\mathrm{y}$ viceversa.

También hay que hacer notar que desde los glosadores hasta nuestros días disponemos prácticamente de los mismos términos, pero con variaciones en su semántica de tal irreversibilidad que nos atrevemos a clasificarlas de perversas, por cuanto en algunos casos son opuestas al sentido original latino. Por ejemplo, el término «auctoritas» que en su versión moderna "régimen autoritario" tiene el significado contrario a lo que «autoritas» significaba durante la República romana. Los conceptos de autoridad, y poder se emplean en diversos sentidos en el ámbito de la filosofía política y de las ciencias sociales, en ocasiones sin la necesaria exactitud semántica para evitar equívocos. Tal diversidad se debe, en parte, a la ubicuidad del fenómeno ${ }^{11}$.

Por tanto, el término «autorictas» no es univoco, Royo Arpón ${ }^{12}$ sitúa la noción del concepto entre los términos de abstracción, refiriendo el concepto a la cualidad de preeminencia social del augur y que se atribuye a personas e instituciones, en tanto que deben decidir sobre personas o cosas en función de su preeminencia, personal o institucional, que los demás atribuyen o reconocen. Para Royo Arpón, de forma literal, el vocablo «auctoritas» encierra en sí una cierta tensión entre la idea de conocimiento o ciencia de alguien y su reconocimiento social, por lo que fue adquiriendo el sentido que aporta Cicerón en Verr. $4,25^{13}$. Por otra parte, a juicio del autor, en el sentido de este vocablo concurre una doble perspectiva, esto es, el de quién la ostenta y el de quienes se la atribuyen. Por ello, para Royo Arpón, resulta idónea nuestra palabra «auctoritas» en el sentido de describir la razón o justificación del ejercicio material del poder en todos los ámbitos, público y privado. Sin embargo, consideramos que el soporte, el sostén del poder no resulta ser la «auctoritas», ya

${ }^{10}$ Domingo, Rafael (1987) Capítulo I. «Auctoritas y «Potestas» en la experiencia romana. en "Teoría de la "auctoritas». Ed. EUNSA, Pamplona, págs. 55-104.

11 "..la terminología ha sido siempre la paralización del pensamiento. No para el que la crea, sino para el que se sirve de ella sin una previa reflexión sobre los pasos que el lenguaje ha dado hasta finalizar en el término». Cfr. Emilio Lledó. "Filosofía y lenguaje". Ed. Austral 4ª Ed. Barcelona 2015. 192 páginas.

12 Este profesor lleva a cabo un estudio que comprende aspectos filológicos e históricos de los términos latinos que poseen algún sentido de poder, ya sea público o privado, así como un análisis de la deformación que han sufrido dichos vocablos, fruto de los añadidos semánticos que la propia Historia ha ido aportando, para finalmente llegar a circunscribir el significante auctoritas al grupo de vocablos que el autor denomina "palabras con poder". Royo Arpón, J. Ma. “Palabras con poder”. Ed. Marcial Pons Madrid, 1997.153 págs.

${ }^{13}$ Cic. Verr. 4, 25: "Honos habetur ordinis auctoritati, quae nisi gravis esset apud socios (...), ubi erit imperi nomen et dignitas» 
que para su justificación no requiere necesariamente el reconocimiento por parte de otros, sino que bastará con una causa basada en una suprema prerrogativa rectora y coactiva para sostenerse. ${ }^{14}$ Por tanto nos proponemos investigar si la «auctoritas y la potestas» han muerto en nuestras sociedades occidentales.

\section{Conformación de la época moderna}

PARA COMPRENDER MEJOR LOS TÉRMINOS de «auctoritas y potestas» en el contexto de la época moderna, consideramos necesario realizar una revisión previa de los rasgos más importantes de esta etapa, así como la realización de algunas aclaraciones. En suma, en este apartado pretendemos elaborar el contexto en el que insertaremos posteriormente los términos de "auctoritas y potestas». Así, la Edad Moderna, que se extiende desde mediados del siglo XV hasta el comienzo de la Edad Contemporánea en 1789, supuso la confirmación de la destrucción de los pilares que se habían ido conformando a lo largo de la Edad Media, y su sustitución por otros nuevos. El imaginario constituido en la Edad Moderna dejó unas huellas que aún se pueden advertir en la actualidad. Por tanto, la época moderna se caracteriza por la orientación y apertura al futuro y a la novedad. Utilizaremos en adelante el concepto de época ${ }^{15}$ (moderna), pues nos parece lo más adecuado dada la significación del término anterior a la que conocemos actualmente.

Así, el término época, antes de referirse a un intervalo de tiempo, "se comprendía como el punto de inflexión a partir del cual se podía contemplar lo pasado y lo que estaba por venir. La concepción del concepto de época, lo podemos considerar como un punto de pausa de un movimiento y también el punto en que se producía un cambio de dirección. Por tanto, el paso de una época a otra supone la noción de umbral, es decir, el momento en que se produce el cambio de una época a otra" ${ }^{16}$. En el caso de la época moderna, el comienzo puede fijarse en $1543^{17}$. En ese ańo, donde se hizo pública la obra del astrónomo, gracias al empleo de cálculos matemáticos, Nicolás Copérnico postuló el heliocentrismo, con base en la concepción formulada por Aristarco de Samos ${ }^{18}$ hacia el 300 a. C. La teoría de Copérnico pos-

${ }_{14}$ Royo Arpón, J. Ma. “Palabras con poder”, Madrid, 1997. pág. 31, nota 12.

15 Diccionario de Filosofía. Ferrater Mora. Tomo II. Ed. Ariel. 2a edición, marzo 2.009. Págs. 1232-123

${ }_{16}$ Martínez Martínez, Francisco José: “Pensar hoy: Una ontología del presente”. pp. 17-50

${ }_{17}$ En el ańo 1543, pocos días después de la muerte de su autor, se publicó la obra «De revolutionibus orbium coelestium» (sobre las revoluciones de las esferas celestes) de Nicolás Copérnico (1473-1543), astrónomo y sacerdote nacido en Torum (Polonia). Nicolás Copérnico. De la Revolución de las Esferas Celestes, Libro L. Véase Thomas S. Kuhn, The Copernican Rroolutian (Nueva York: Vintage, 1957), p. 154.

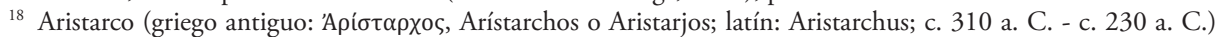
fue un matemático y astrónomo griego, originario de Samos. Según los conocimientos actuales, Aristarco fue el 
tulaba que el Sol era el centro del universo, y que en torno a él giraban la Tierra y todos los planetas. Este hecho marcó el inicio de una nueva época, la época moderna.

La época moderna supone, pues, la construcción de un nuevo orden en todos los sentidos, pero su inicio, que coincide históricamente con la etapa del Renacimiento, es además una etapa de transición entre los hábitos y pensamientos medievales y los modernos, que ocuparán el imaginario colectivo durante los próximos siglos. La sociedad feudal como base y la Iglesia y la monarquía como cúspides del sistema son elementos fundamentales del Antiguo Régimen que, si bien como hemos mencionado se mantuvo hasta finales del siglo XVIII, no siempre fue con la misma fuerza con la que se inició. La transición se produjo en todos los grandes pilares de la vida del ser humano: cultura, sociedad, religión, economía, política,...El Antiguo Régimen, conjunto de rasgos políticos, sociales y económicos, herederos en gran medida de los medievales y predecesores del posterior sistema capitalista de clases, fue el sistema por el que la sociedad se rigió durante la época moderna.

Podríamos considerar que la época moderna fue una etapa de tensión y de prevalencia del par continuidad-discontinuidad y tradición-progreso. El antropocentrismo sustituyó al teocentrismo imperante durante la época medieval, basado en el desarrollo de las ciencias y las ciencias humanas. El paso del teocentrismo al antropocentrismo no se trató de una negación hacia Dios, la Iglesia o los valores de esta institución, sino más bien de una reivindicación de la importancia del ser humano y su valor, de la razón y el intelecto como puntos de partida para el progreso y como cimientos del pensamiento humano. La modernidad, en definitiva, planteó la cuestión de la diversidad de opiniones y credos, debido a la interpretación libre de la Biblia ${ }^{19}$, dando lugar a una serie de cambios sociales, como puede ser el fomento de un nuevo sentimiento de nación, el incremento del prestigio y uso de las lenguas vernáculas, también un cambio en la actitud hacia el arte, el trabajo y la emoción humana, además de dar lugar a una pérdida del sentido de unidad en Occidente. Fue una etapa de transición, lo que implicó la ruptura de las bases anteriores, la construcción de nuevas bases y la inestabilidad general. Por lo tanto, las

primero en proponer el modelo heliocéntrico como alternativa al modelo geocéntrico que se consideraba entonces irrefutable. Mediante esta nueva forma de entender el mundo, era el Sol y no la Tierra el centro de nuestro universo. Diccionario de Filosofía. José Ferrater Mora. Volumen I. Ed. Alianza Editorial. 7a reimpresión, 1990, Madrid. Pág. 203-204.

19 Martín Lutero y su proclamación de las 95 tesis dirigida a la Iglesia de Roma, en la que desacredita la doctrina papal sobre las indulgencias. Esta publicación — clavada por Lutero, de acuerdo a la tradición, en las puertas de la Iglesia del Palacio de Wittenberg el 31 de octubre de 1517- comenzaría un debate teológico que desembocaría en la Reforma y el nacimiento de varias tradiciones dentro del cristianismo, tales como el luteranismo, el presbiterianismo y el anabaptismo. En su opinión, las autoridades eclesiásticas habían dejado de lado su papel espiritual y moral. Dando mayor importancia a su dimensión terrenal política. https://www.wdl.org/es/ item/7497/ 
paradojas durante este período son frecuentes, ya que podemos apreciar en él tanto rasgos tardo medievales como modernos que son contrarios y que incrementaron la sensación de inestabilidad que reinaba.

Para la filosofía, la época moderna fue un período de gran ebullición intelectual, quizás porque se trata de una de las etapas donde se hace más presente el dualismo continuidad-discontinuidad y su continua tensión entre el pasado y el futuro, con una identidad construida entre ambos. La búsqueda de respuestas en base a la razón y a la verdad, la defensa del intelectualismo y del pensamiento humano, dieron lugar a la proliferación de múltiples corrientes de pensamiento que sería imposible abordar en este artículo por razones de complejidad y espacio. Por ello, tras la concisa revisión realizada en torno a la época moderna, hemos optado por centrarnos en los dos términos incluidos en el título de nuestro artículo, "auctoritas y potestas", al considerar su relevancia como nexo entre filosofía, política y sociedad, elementos imprescindibles de la época moderna ${ }^{20}$. Por tanto, esperamos que la visión del tratamiento y significación de ambos conceptos durante la época moderna arroje luz sobre una de las etapas más ricas y complejas de la historia del ser humano. El pensamiento de autores como Hegel, Kant o Locke son fundamentales para comprender la aplicación de la «auctoritas» y la "potestas» durante la época moderna, y a ellos nos remitiremos para entender la complejidad de la etapa que nos concierne.

Por lo tanto, en lo referido a la disciplina filosófica, lo moderno hace referencia a todo aquello que posee un vínculo con la Modernidad en lo que se refiere al ZEITGEIST o espiritu de época en el que surge y progresa el capitalismo. Durante la modernidad, se desplegó una multiplicidad de corrientes culturales e intelectuales que nos lleva a pensar que la misma, es el crisol de diferentes formas de asumir esta etapa que abarcaría los siglos del XVII al XX. Pasemos por tanto a los conceptos de «auctoritas y potestas» en la época moderna.

\section{Los conceptos auctoritas y potestas durante la época moderna}

LA FILOSOFÍA MODERNA DETERMINÓ enormemente la concepción y significación de diversos términos que han evolucionado a lo largo de la historia del ser humano, entre ellos los de «auctoritas y potestas». Esto se debe a que los filósofos contribuyeron con sus obras y pensamientos a la reestructuración de los pilares fijados hasta la llegada de la época moderna; si bien es cierto que la evolución se advirtió progre-

\footnotetext{
${ }^{20}$ Véase el artículo de Edgar Streahel "Algunas claves para una relectura de la autoridad” en Las Torres de Lucca, n⿳亠 7 Julio -Diciembre 2015: 171-207. http://www.lastorresdelucca.org/index.php/ojs/article/view/76/68
} 
sivamente y que podemos hablar de un cambio significativo a partir de los siglos XVII y XVIII, dado que los dos siglos anteriores pueden considerarse realmente como una etapa de transición entre el Antiguo y el Nuevo Régimen. Por tanto, la época moderna es deudora de las tensiones que se configuraron tanto en la Baja (476 -1100 d.c) como Alta (1100-1453 d.c) Edad Media, en torno a los vocablos de la «auctoritas y de la potestas». Así tenemos que tanto la Iglesia como los Reyes mantenían una tensión en cuanto al poder espiritual y terrenal, donde hubo periodos donde se superponían en una misma figura o bien predominaba uno sobre el otro, con la característica de sus rivalidades y luchas para que predominara uno sobre el otro. En este sentido, con en el progresivo devenir histórico y las circunstancias acaecidas fundamentalmente en Europa (Italia), se fue diluyendo la situación anterior mediante las reflexiones y aportaciones de pensadores tardomedievales, que veían en la unión de estos dos poderes concentrados en el Papa, el declive del poder celestial por conllevar aspectos oscuros que contradecían el propio Evangelio. Es en este ámbito donde la figura de Marsilio de Padua (1275-1342) juega un papel fundamental, siendo defensor de la separación entre el poder temporal y el poder religioso ${ }^{21}$. Incluso se le ha llamado "paladín del dualismo" de poderes ${ }^{22}$ porque en su obra la independencia del poder alcanzaría el máximo grado y no habría «un dualismo tan perfecto como el propuesto por Marsilio» ${ }^{23}$. Aunque expone que el rechazo de cualquier autoridad distinta de la civil no conlleva la negación del poder celestial, sencillamente no podían estar en un mismo plano. Por ello el juicio y la sanción de la ley divina, cuyo autor inmediato y exclusivo es Dios, no tiene lugar en esta vida sino en la otra y, por tanto, no da a nadie en este mundo un poder coactivo distinto del que le corresponde al legislador humano sobre todos los actos humanos civiles.

Por tanto, para Marsilio de Padua, el clero carece de competencia para legislar, y su insistencia no tiene fundamento y genera graves inconvenientes y problemas, el peor de los cuales es la disensión provocada por la multiplicidad de poderes coactivos, que alimenta la confusión y la contradicción, porque da la sensación de que las leyes humanas son superfluas ${ }^{24}$. Por tanto, la filosofía política marsiliana es deudora del momento histórico donde se fraguó, en cuanto que en ella el problema sobre el

${ }_{21}$ Roche, P., (1995) «La "plenitudo potestatis" en el "Defensor minor" de Marsilio de Padua", en Éndoxa, 6. UNED, Madrid. Págs. 241- 262 y La ley en el "Defensor minor" de Marsilio de Padua", Revista Española de Filosofía Medieval, 2 (1995a), pp. 91-99.

22 Watt, J.A, (1991) «Spiritual and temporal powers», en Burns, J. H. (ed.), The Cambridge History of Medieval Political Thought, c.350-c.1450, Cambridge University press, 1991, pág. 411.

${ }^{23}$ Mcllwain, C. H. (1932) «The Growth of Political Thought in the West", New York, Macmillan, p. 313.

${ }^{24}$ De Padua, Marsilio ([1341] 1979) "Defensor Minor", edición francesa de J. Quillet, Marsile de Padoue, Oeuvres Mineures, Paris, Editions du Centre National de la Recherche Scientifique, II, 5, p. 88. El número romano corresponde al capítulo y el número arábigo al parágrafo. En otras citaciones esta obra aparecerá como DM. 
poder es la lucha entre los dos poderes medievales ${ }^{25}$, y a la vez, su obra se convierte en la antesala del Estado Moderno ${ }^{26}$. Marsilio escribe su obra desde la crítica -vocablo éste genuinamente moderno- de una práctica política y con la vocación de convertirse en programa para cambiar una situación histórica y lograr la paz. Dando lugar a una teoría de validez general del poder de forma racional. Su obra es por completo filosofía política, en el mismo sentido en que se lo podemos atribuirá a Hobbes, que justifica el poder del soberano, o la de Marx, cuya crítica teórica de la sociedad de clases se orienta a la superación de la división social.

En cuanto a los conceptos que ocupan nuestro artículo, la época moderna modificó el sentido de ambos, puesto que impugnaba la «auctoritas y la potestas» de la Iglesia de Roma, y con ello se quería sustituir la autoridad del Papa por la conciencia personal, es decir, la razón individual o subjetiva se constituye en la nueva auto$\operatorname{ridad}^{27}$. Siendo el ámbito por excelencia de la razón moderna, el mundo académico y científico; el lugar natural del sujeto de la modernidad y de los valores ilustrados, fundamento de una identidad clara y precisa surgida en el siglo xviI a partir del «cogito» cartesiano, que se consolida en los siglos siguientes al mismo tiempo que la idea de modernidad centrada en la razón como motor y norma de la sociedad. La idea de sujeto que se deriva de estas ideas es, por lo tanto, un ser consciente, indiviso, controlado, razonable y, por lo tanto, moderno. Por eso se viene a sustituir la «auctoritas» de la Iglesia, monolítica y unitaria, a la que se denominó de oscurantista y autoritaria, por una autoridad subjetiva, basada en la propia reflexión y cimentada en la ciencia como nueva «auctoritas» mundana, en contraposición a la que devenía de las Sagradas Escrituras.

La invención de la imprenta de Gutenberg sirvió en gran medida a que el concepto de "auctoritas" se desplazase desde los monasterios a las universidades, es decir, favoreció el paso de la cultura eclesiástica a la cultura laica. Esta transformación

25 Padua, Marsilio. ([1324] 1999) “Defensor Pacis”. Trad. Luís Martínez Gómez. "El Defensor de la paz”. Ed. Técnos, Madrid."

${ }^{26}$ Bayona, Bernardo. (2007). "Religión y poder. Marsilio de Padua: ¿la primera teoría laica del Estado?, Biblioteca Nueva-Prensas Universitarias, Madrid. pp. 107-148 y García Cue, J. R.(1985) «Teoría de la ley y de la soberanía popular en el "Defensor pacis" de Marsilio de Padua", Revista de Estudios Políticos, 43

27 Frank Furedi, Authority: A Sociological History, Cambridge University Press (October 28, 2013), 453 pages. "La preocupación por la autoridad es tan antigua como la historia de la humanidad misma. El pecado de Eva era desafiar la autoridad de Dios al desobedecer su gobierno. Frank Furedi explora cómo la autoridad fue disputada en la antigua Grecia y le da un significado de gran alcance en la Roma Imperial. Los debates sobre la autoridad religiosa y secular dominaron Europa durante la Edad Media y la Reforma. El mundo moderno intentó desarrollar nuevas bases para la autoridad —el consentimiento democrático, la opinión pública, la ciencia-; sin embargo, Furedi muestra que este problema sigue sin resolverse, con el argumento de que hoy se pone en duda la autoridad de la autoridad. Esta sociología histórica de la autoridad pretende explicar cómo los problemas contemporáneos de la desconfianza y la pérdida de legitimidad de muchas instituciones son informados por los intentos anteriores para resolver el problema de la autoridad" 
en la comprensión del mundo supuso también consecuencias, puesto que para los modernos "el tiempo ha dejado de prometer algo" ${ }^{28}$, dice Myriam Revault, ya que el pasado no garantiza el futuro y debido a esto lo vuelve incierto, fundamentalmente porque la modernidad cree más bien en el progreso que en un Dios no ligado ya a ninguna consecuencia de sus manifestaciones, por lo que el tiempo pasa a ser la dimensión de la incertidumbre absoluta, o como apunta Blumberg: "La temporalidad se convierte en el hándicap decisivo del espíritu humano" 29 .

La supremacía de la razón durante la época moderna podría describirse como una "hegemonía de la episteme" ${ }^{30}$, ya que el empirismo y el racionalismo fueron las doctrinas predominantes durante esta etapa. El ser humano se convierte en un ser trascendental, consciente de sí mismo y del mundo que le rodea, inmerso en la incertidumbre del futuro y del tiempo. Esta situación se refleja o, más bien, se vincula con la transformación de la relación entre "signo y significado, que pasa de ser terciaria -marca, contenido, similitud-, a ser binaria y estable -significante, significado-" 31 . Ya no se trata de reconocer los símbolos que nos transmite el mundo que nos rodea, sino de ir más allá, de conocerlos.

La transcripción del mundo se convierte en un conocimiento directo del mundo; la unión entre las palabras y las realidades a las que representan es cada vez más débil. Por otro lado, en la doctrina filosófica se produce un hecho fundamental: la conciencia desdichada o la disociación entre el ser y el hombre. Descartes será una figura decisiva en la conformación de las ideas filosóficas imperantes durante la época moderna, con su «cogito ergo sum», a partir del cual podemos comprobar que el hombre moderno ya no parte de lo divino para entender el mundo, sino de sí mismo, por lo que asistimos a una reconstrucción de la realidad a partir del hombre mediante el uso de la razón y la lógica. Los pensamientos onto-epistemológicos de Kant y Hegel, como mencionamos anteriormente, serán también decisivos, así como la filosofía política de Kant y de Locke.

Kant es consciente de la paradoja a la que se enfrenta el hombre de su tiempo: la confianza en el hombre y en la razón surgida en la época moderna y la conciencia desdichada provocada, a su vez, por los avances del desarrollo de la razón. El ser humano es ahora consciente de su conocimiento, pero también de sus límites y de su desconocimiento. En Hegel, encontramos la misma raíz del pensamiento manifestado en lo que conocemos como auto-conciencia, la confirmación de sabernos como sujetos rodeados de objetos, de realidades que anhelamos conocer. El «Sapere

\footnotetext{
28 Óp. Cit. "El poder de los comienzos" pág. 134

29 Blumenberg, Hans. "La legitimación de la edad moderna". Ed. Pre-textos, Valencia, 1 Edición 2.008. pág. 156

${ }_{30}$ Márquez, Esther "La paradoja de la modernidad". 2015. pág. 112. http://hdl.handle.net/10810/18516

31 Ibíd. Pág. 91
} 
aude» de Kant y la auto-conciencia ${ }^{32}$ de Hegel, citando de forma concisa dos de los principales elementos de las filosofías de ambos autores, forman parte de los cimientos del pensamiento moderno.

Si bien las ideas en cuanto al ser y el mundo propuestas por la filosofía moderna son atractivas y determinantes en la historia de la filosofía y del ser humano, por motivos de extensión y de temática la cuestión que nos preocupa es la concepción de Estado que manifestaron los filósofos mencionados durante la época moderna. La filosofía política distingue cuatro tipos de Estados principalmente: absolutista, liberal, democrático y ético ${ }^{33}$. Kant y Locke fueron defensores del Estado liberal, sobre todo Locke, uno de los principales precursores y defensores de la doctrina del liberalismo; mientras que Hegel fue el máximo exponente del Estado ético.

El Estado liberal no se comprende sin el principio de libertad, ya que es el fundamento de esta doctrina. Como seres sociales que somos los humanos, vivimos en sociedad; una sociedad basada en un cierto orden, que varía en función del lugar y las características de las personas que forman dicha sociedad. Por ello, para el liberalismo, el fin es que los derechos y garantías de las personas estén asegurados por quienes ostentan el poder, es decir, por el poder político. El poder político debe asegurar los derechos individuales, pero al mismo tiempo debe respetar el principio fundamental del liberalismo, la libertad. Según Locke y su doctrina jusnaturalista, "todos los hombres poseen por naturaleza ciertos derechos esenciales aglutinados, en sentido amplio, bajo el concepto de propiedad: derecho de propiedad a la vida, a la propiedad de la libertad y a la propiedad de las posesiones materiales" 34 . Al tratarse de derechos naturales, significa que no vienen dados por la construcción social y política, sino que esta última debe asegurarlos porque nos vienen dados de por sí. Este factor determina otro de los principios fundamentales del liberalismo: la separación entre el espacio individual o privado y el público. Un Estado liberal debe fijar los límites entre ambos y sus representantes políticos no deben traspasar dichos límites, respetando siempre la privacidad y libertad del individuo. Siendo estos argumentos el que reforzó la idea de la separación entre Iglesia-Estado, y que hoy es generalmente admitida en las democracias occidentales, forjada en paralelo con la de la moderación epistemológica y política, dando lugar a una separación de la «auctoritas y potestas» de la iglesia, en beneficio del Estado, al cual hay que conformar para darle una legítima posición en los asuntos terrenales. Por tanto, para explicar el poder político,

\footnotetext{
${ }^{32}$ Hegel W.F. (1966). Fenomenología del espiritu. México: Fondo de Cultura Económica. pág.107.

${ }_{33}$ Rubén R. Dri. "La filosofía del Estado ético. La concepción hegeliana del Estado". En Atilio A. Boron. "La filosofía politica moderna". 2000. Págs. 214-215.

${ }^{34}$ Locke, John. Capítulo V: "De la propiedad". págs. 55-75. en "Segundo Tratado sobre el gobierno civil". Trad. De Carlos Mellizo. Ed. Alianza., Madrid, 2012.
} 
de modo que sea racionalmente legítimo hay que seguir otro camino basado no en la primacía de la tradición, sino en el de la razón y el individuo.

Kant, por su parte, está de acuerdo con Locke en algunos de los principios del liberalismo jusnaturalista, como la dualidad que se da en el ser humano entre el estado de naturaleza y el de sociedad. El estado de naturaleza en el que se encuentra el hombre antes de la creación de la sociedad, es la ausencia de los principios normativos que regulan las relaciones entre individuos, por tanto es un estado sin ley y salvaje, un estado de guerra. La inseguridad en el Estado no depende de que no haya en el ningún derecho, sino de que no hay en ese estado un derecho público - «auctoritas»-, que cuente con el respaldo de un poder que haga cumplir las leyes - - potestas»-. Kant considera que el pacto social, es la primera obligación moral que nos propusimos las personas: salir del estado de naturaleza y buscar la paz, la justicia y la libertad. Un hombre en el estado de naturaleza es una amenaza. Para el filósofo alemán, los seres humanos deben transformar su estado natural en una sociedad civil que garantice sus derechos y libertades.

Hegel, sin embargo, es uno de los representantes del Estado ético, por lo que su teoría se desliga de la de Kant y Locke. Siguiendo la definición de Dri, el Estado ético

"es el Estado como plena realización de los seres humanos mediante una dialéctica que incorpora por vía de superación todos los logros de la historia, desde el derecho, pasando por la moral individual, para culminar en la eticidad, matriz de los valores más altos de la humanidad, expresados en el arte, la religión y la filosofía." 35

Como podemos observar, la definición de Estado ético tiene que ver con la idea de contrato social. Mediante la creación y consolidación de un contrato social, voluntad y libertad se relacionan y esta última se diferencia de la idea de libertad como libre albedrío, tal y como se entendía en el liberalismo. Se es libre cuando se es consciente y cuando se posee voluntad para serlo, más allá de la simple toma de decisiones. Según Hegel, y aquí podemos apreciar su excesivo optimismo, las libertades y derechos de los ciudadanos pueden garantizarse a través de la mediación y el diálogo, en tanto que los propios individuos respetarán las libertades del resto al comprender que precisan las mismas que ellos.

Las ideas del liberalismo, sin embargo, se implantaron progresivamente y no es hasta el siglo XVIII cuando se puede hablar realmente de liberalismo, ya que

\footnotetext{
${ }^{35}$ Rubén R. Dri. "La filosofia del Estado ético. La concepción hegeliana del Estado". En Atilio A. Boron. "La filosofía politica moderna”. 2000. Pág. 215.
} 
hasta entonces la forma predominante del Estado era el absolutismo. La «auctoritas y la potestas» no poseen, por tanto, el mismo significado en una y otra etapa, sino que evolucionaron conjuntamente y, además, ocasionaron numerosas confusiones. Para comprender mejor ambos conceptos, recurrimos a Álvaro D'Ors, uno de los principales filósofos políticos, quien identifica la autoridad con el saber y la potestad con el poder, teniendo ambas como base el reconocimiento social. Durante los primeros siglos de la época moderna, con el absolutismo como principal forma de Estado, era una misma persona quien ostentaba la autoridad y la potestad, al menos en teoría.

En realidad, si nos dirigimos a ambos conceptos y nos aproximamos a ellos, podríamos considerar que realmente el Estado moderno de los siglos XV, XVI y XVII no reflejaba autoridad y potestad, sino más bien autoritarismo, y nuestro pensamiento se debe a dos razones principales: 1 . el soberano era impuesto indistintantemente de si los ciudadanos lo aceptaban o no, es decir, el reconocimiento social no se tenía en cuenta en la monarquía absoluta; 2 . el monarca adquiría su papel de nacimiento, mediante la divinidad, según las creencias de la época, por lo que poco importaba su grado de poder y de saber; por lo tanto, su capacidad para reinar y su sabiduría no eran determinantes para que el individuo en cuestión reinara o no. Gracias al desarrollo del liberalismo, sí podemos hablar de la manifestación de autoridad y potestad en los posteriores sistemas políticos, puesto que se tenía en cuenta la opinión y querencia de los ciudadanos, por una parte, y las capacidades de los aspirantes a adquirir el poder político, por otra.

La separación de poderes es un elemento fundamental que, además, nos indica que la potestad y la autoridad son, en definitiva, más que conceptos, son complejos sistemas que no pueden ni deben reducirse a unas simples características, ya que dependen de diversos factores como el tiempo o el lugar en que se inscriben. Pero, sobre todo, se trata de dos conceptos ante los que se debe ser cauteloso, pues el poder es fácilmente corruptible, debido a las aspiraciones individuales y al egoísmo al que estas pueden dar lugar. En relación con el liberalismo defendido por Locke, Kant y Hegel, el poder debe partir siempre de la razón y de la buena fe con respecto al otro, de la garantía del cumplimiento de la ley y de la satisfacción de las libertades.

Por otro lado, la pérdida de atención a la "auctoritas" de la Iglesia ya había comenzado mediante el proceso de secularización. La Reforma Protestante fue, en gran medida, la causa histórica de que, rota ya la unidad religiosa europea, se buscase edificar una nueva forma de unidad, que se concretó en el surgimiento de los Estados Nacionales bajo regímenes absolutistas o constitucionalistas como el caso de Inglaterra y Holanda. El absolutismo, a su vez, fundió en una misma persona la misión de gobierno político (ejercicio de la "potestas») y la misión de enseñanza y 
juicio (ejercicio de la auctoritas»), dando comienzo a la confusión práctica de estas funciones. La pérdida de limitación del poder, debida a que la potestad había absorbido a la autoridad, condujo progresivamente al crecimiento desmedido del Estado. De lo expresado anteriormente, se puede establecer el dilema en la cual se sitúa Álvaro D'Ors para ir determinando con el transcurrir del tiempo y las circunstancias, el desarrollo histórico del Estado Moderno; cuya raíz sitúa fundamentalmente en el protestantismo: "que supuso la ruptura ontológica más honda entre la «auctoritas y la potestas", y que trajo consigo la muerte de la primera en aras del desmedido crecimiento de la segunda" ${ }^{36}$. En un mundo laicista y crecientemente individualista se desarrolla con fuerza la noción de Derecho subjetivo.

No obstante, estas raíces individualistas y mundanas, unidas a la idea calvinista de que la predestinación divina se manifiesta en la riqueza, allanaron el camino para el desarrollo de un capitalismo desenfrenado. Pues bien, la «auctoritas» (siempre intelectual) quedó definitivamente subordinada a la "potestas» en el protestantismo calvinista, mientras que la potestad (manifestación de poder de la voluntad) fue magnificada. Por lo que la crisis de autoridad se va presentando paulatinamente en la época moderna fundamentalmente, debido a la ruptura con la tradición y se manifiesta en la noción misma de temporalidad ${ }^{37}$, donde se quiere romper la relación del presente con el pasado, fundamentalmente con la Edad Media, no así con la cultura clásica, debido a que se revaloriza la vuelta a los ideales grecolatinos.

\section{Conclusiones}

EN la ACTUALIDAD, se habla de la crisis de la modernidad, debido a que evidentemente el sujeto racional cartesiano («cogito ergo sum») no ha podido colmar la sed

36 D’Ors, Álvaro (1987) La Violencia y el Orden. Madrid: Dyrsa. pág. 24.

37 "Con la revolución científica, especialmente a partir de Galileo, la noción de tiempo cambia drásticamente. Aparece la noción de un tiempo abstracto, concebido como un parámetro o una variable física que vale para todo movimiento, y no sólo para el uniforme, como lo había considerado Aristóteles. Galileo, al estudiar el problema de la velocidad instantánea de un cuerpo en movimiento, da un nuevo impulso en la comprensión de la noción de tiempo, a la vez que suscita los problemas que darán lugar a la aparición del cálculo infinitesimal. Entonces se empieza a desarrollar el otro camino de investigación que el mismo Aristóteles había apuntado. Tiempo, espacio y materia serán los tres grandes conceptos de la física moderna clásica, es decir, del mecanicismo. Así, desvinculado de su relación con el alma, el análisis del tiempo se enfocó desde la perspectiva física. No obstante, se podía entender de dos maneras distintas: como una realidad absoluta o como una relación. Estas dos maneras de enfocar el tiempo enfrentaron a Newton, que defendía un tiempo absoluto (y lo consideraba como sensorium Dei, y como una especie de continente vacío), y a Leibniz, quien lo consideraba como una relación (el orden universal de los cambios, el orden de sucesiones). Adoptando la terminología kantiana, síntesis de las anteriores, el tiempo es una intuición pura o una forma a priori, y, junto al espacio, constituyen ambos la forma de percepción posible desde la perspectiva de la sensibilidad”. https://www.rafaelpenalver.es/148862520 
de los grandes interrogantes del hombre ${ }^{38}$. Pero ante esta crisis de valores, donde se cuestionan la época moderna con su razón cartesiana, su antropocentrismo, su escepticismo ante la metafísica y su imperativo categórico, pareciera que detrás de esta aparente "liberación del hombre", se encuentran unas estructuras, valores y actitudes tanto o más autoritarias que el autoritarismo moderno, del cual quieren emanciparse. Para ello sería conveniente observar la tradición y los prejuicios, de los cuales la época moderna quiso desembarazarse, precisando cuáles de ellos siguen latiendo dentro de nuestra concepción del individuo y de la sociedad actual. Es decir: ¿¿deberíamos sin más desdeñar la «auctoritas y la «potestas» y someternos a un autoritarismo no tan visible —imperium (capitalismo financiero y especulativo) pero presente en nuestras sociedades occidentales, de tal manera que el hombre no tenga un centro desde el cual poder construir su vida y posibilidades como persona? Si asumimos el paradigma cartesiano de tabla rasa, quizás la crisis de la Modernidad sea su incapacidad para perpetuarse sine die sobre un continuo presente vacío. Mientras que, si hablamos de la crisis de la Modernidad humanista, habría que retomar los postulados de ésta, adecuándolos a nuestro tiempo, pero sin olvidar que el hombre se debe a una herencia del pasado, de la cual habrá de ser hermeneuta.

Por lo anteriormente expresado, nos cabe la pregunta de la introducción: ¿Nos encontramos, pues ante la muerte de la "auctoritas» $y$ de la "potestas»? Así el Estado moderno se compone de individuos y no de un cuerpo social vertebrado. La sociedad se edifica sobre un individualismo intrínseco que considera a la persona como un agente económico que actúa en el mercado, como un voto o un sujeto de imputación jurídica. Se conforma así una total subversión de los subsistemas sociales, que se caracterizan por una concepción antropológica, filosófica, económica, política o jurídica de la persona que pone de manifiesto que sólo el poder resulta hoy valorado. Por consiguiente, podría plantearse que cuando la autoridad y la potestad se encuentran en equilibrio, es sano para el desenvolvimiento de la sociedad considerarlas del siguiente modo: "autoridad como la verdad socialmente reconocida y la potestad como la voluntad de poder socialmente reconocida ${ }^{39}$ ". Ambos conceptos llevan a continuación una nota explicativa en donde la autoridad se equipara con el "prestigio del saber", que se manifiesta a través del "consejo" y, primordialmente, es la única instancia capaz de actuar como "límite de la potestad". La autoridad, al ser "saber", es personalísima y, por tanto, indelegable. La potestad, por su parte, es indivisible, y delegable.

38 Juan Antonio Estrada "Raíces filosóficas de la increencia: De Descartes a la modernidad". En Razón y Fe. Págs. 305-324. Tomo 222-No1.105- noviembre 1990.

39 D’Ors, Álvaro (1973) “Autoridad y potestad" en "Escritos varios sobre el derecho en crisis". Pág. 93. Ed. C.S.I.C. Delegación en Roma. No24. Roma- Madrid 
La situación anterior crea un conflicto que surge cuando se cuestiona la tradición, como fundamento de un continum temporal que enlaza el pasado con lo por venir, entonces lo que ha mostrado su validez en el pasado pierde dicha validez y la multiplicidad de posibilidades amenaza a un presente basado solamente en un día a día carente de orientación y esperanza. Sin embargo, existe una opción ante el politeísmo de valores y los modos antagónicos de legitimidad ${ }^{40}$, ya que nuestro raciocinio y nuestra capacidad de acción tienen sentido cuando tratamos de hallar precisamente un sentido al mundo, a la realidad existente. El nuevo sentido no surge de la nada, no es una construcción ex nihilo, sino que se nos exige su conquista, que se reconstruye y se reconquista de nuevo, como si se tratara de empezar de nuevo partiendo de nuestras tradiciones, es decir el continum temporal. Por lo que estamos de acuerdo en lo que Revault d'Allonnes sostiene, y es que no asistimos al vaciamiento o pérdida de sentido de la "auctoritas", sino a su diversificación, y este hecho es crucial en lo que concierne a la cuestión de la autoridad, siendo la tesis fuerte que plantea esta autora la de la transformación de la autoridad, desde la tradición hasta la transmisión. De ese modo, la autora argumenta que lo referido al problema de la autoridad actual está orientado hacia nuestro futuro.

Ahora bien hay que recordar que el Estado Moderno reconoce al individuo, una abstracción hecha por los grupos en los que vive. La sociedad en sus múltiples formas es extraña a ella. Por lo tanto, se podría considerar que es liberal e indiferente a ciertas preocupaciones colectivas, considerando que su tarea legal se ha agotado y termina demostrando ser impotente para regular la vida de las clases más bajas, cuando estas en el siglo XIX comenzaron a adquirir importancia. De ahí que lo que se ha llamado "crisis del Estado" del siglo XIX, como la necesidad de una mayor integración, que, si en el orden práctico encontró recientemente su realidad con el fascismo, en el orden teórico ya había sido observado necesario por varios autores. El Estado fascista tenía el deber de reafirmar la autoridad del Estado -tanto la «auctoritas» como la "potestas»- sobre todas las formas de asociación y de extender su acción a muchos de esos fines, a los cuales el Estado liberal había permanecido ajeno: del progreso económico, al crecimiento de la población, a la educación física, moral y política, el culto y la religión, la asistencia material y sanitaria, hasta la elevación moral de las clases trabajadoras. Cuya acción resultó indispensable para el cuidado de los fines sociales que el Estado había pretendido abandonar a la acción puramente privada de los individuos y que en nuestros días parecen olvidar quienes abogan por un Estado que se preocupe en exclusiva de las funciones de policía, dejando a "la mano invisible" toda la libertad para ejecutar los designios del

$\overline{40}$ Estos dos conceptos se toman de Weber. 
capital especulativo y financiero, lo que conllevaría a un Estado populista ${ }^{41}$, bien sea de derechas o de izquierda, donde la legitimación del poder sólo sea cuestión de convencer con el lenguaje y no con los hechos - la postverdad ${ }^{42}$ - a las masas de ciudadanos que asistimos atónitos a un mundo en que no sabemos ni qué es el bien y ni el mal, que siempre han existidos, pero que en nuestra actualidad aparecen velados por complejos sistemas de autoridades que no se legitiman en la comunidad sino en instancias fuera de control de los ciudadanos.

Incluso se ha llegado a señalar hoy en día la existencia de una moda o una recuperación de la preocupación por de la autoridad ${ }^{43}$ tal como piensa Tavoillot y con el cual estaríamos de acuerdo en el sentido de su falta y de concreción de la misma, pero no en su desaparición: "El diagnóstico es demasiado conocido para detenernos: viviremos, se dice, su crepúsculo, un preludio a su casi desaparición" (...) “'Réquiem in pace, pues! Pero antes de cerrar la lápida y encontrarse abrumado por el dolor o impaciente por la herencia de los funerales con gran pompa, puede estar huyendo de una última oportunidad al último aliento de la muerte." (Tavoillot, 2011 $1^{44}$ )

Por ello, es esencial en estos momentos acordar qué herencia debemos dejar a las generaciones futuras, tanto en lo que se refiere a la auctoritas que nos sostiene como a la potestas a tener en cuenta en nuestras sociedades del siglo XXI. Aunque hay que apostillar que el futuro se nos muestra más bien incierto e inquietante, por las amenazas de guerras nucleares o la verosimilitud de las distopías como las de un mundo feliz de Aldous Huxley o la de George Welles en su libro 1984, basada en la crítica a los totalitarismos y a la opresión del poder.

${ }^{41}$ Cfr. En Malamud, Carlos. "Populismos latinoamericanos. Los tópicos de ayer, hoy y siempre”. Ediciones Nobel, Oviedo 2010 y Zanatta, Loris. "El populismo" Ed. Katz, Argentina 2015. También sería interesante observar la advertencia realizada por Richard Rorty en Forjar nuestro pais. El pensamiento de izquierdas en los Estados Unidos del Siglo XX.. Ed. Paidós, 1989 Madrid.

${ }^{42}$ Cfr. Herrero, Monserrat. Capítulo II: "El poder político del lenguaje” en "Democracia: ¿Conceso o conflicto? Coord. Javier Franzé. Ed. Catarata. Madrid 2014. Págs. 42-62.

43 Ciertamente hay que indicar que en los últimos años se han publicado una serie de libros que han tratado de reivindicar o revisitar la cuestión de la autoridad. Entre otros, véanse Marina, José Antonio, La recuperación de la autoridad: claves para la familia y la escuela, Barcelona, Versátil, 2009; Estlund, David, La autoridad democrática: los fundamentos de las decisiones politicas legitimas, Buenos Aires, Siglo XXI, 2011; Biancu, Stefano, Saggio sull'autorità, Milán, EDUCatt, 2012; Ronell, Avital, Loser sons: Politics and Authority, Urbana, Chicago and Springfield, University of Illinois Press, 2012; Damien, Robert, Eloge de l'autorité: généalogie d'une (dé)raison politique, París, Armand Colin, 2013; Muraro, Luisa, Autorità, Turín, Rosenberg \& Sellier, 2013; Noorani, Tehseen et alii (ed.), Problems of Participation: Reflections on Authority, Democracy and the Struggle for Common Life, Lewes, ARN Press, 2013; Ponce de León, Facundo, Autoridad y poder, Montevideo, Taurus, 2014.

${ }^{4}$ Tavoillot, Pierre-Henri, Qui doit gouverner?: une briève histoire de l'autorité, París, Grasset, 2011, p. 39.Qu'est-ce l'autorité?: "Rien no le montre davantage que la retorur à la mode de la question de l'autorité. Permi toutes ces choses que nos yeux étonnés -et déjà dépassés- voient disparaitre, 1 'autorité occupe en effet la meilleure place. Le diagnostic est trop connu pour que’on s'y arrête: nous vivirons, dit-on, son crépuscule, prélude à sa disparition prochaine. ”. La traducción es mía. 


\section{REFERENCIAS Bibliográficas}

Arendt, H. (1996) ¿Qué es la autoridad? En: Entre el pasado y el futuro. Barcelona: Península. Trad. A. Poljak. Págs. 101-153.

Aristóteles. "Política", Traducción y notas de Manuela García Valdés. Ed. Gredos, Madrid 2007. Libro 1, pág.46-47.

Aurelio Díaz, Jorge. "La estructura de la fenomenología del espíritu" en la revista Ideas Valores, Volumen 36, Número 70, p. 3-32.

Bayona, Bernardo. (2007). "Religión y poder. Marsilio de Padua: ¿la primera teoría laica del Estado?, Biblioteca Nueva-Prensas Universitarias, Madrid.

Bayona, Bernardo. (2007a). El poder y el Papa. Aproximación a la filosofía politica de Marsilio de Padua. ISEGORÍA. Revista de Filosofía Moral y Política N. o 36, enero-junio, 197-218.

Blumenberg, Hans "La legitimación de la edad moderna". Ed. Pre-textos, Valencia, $1^{\circ}$ Edición 2.008

Casinos Mora, F. Javier. "El dualismo autoridad-potestad como fundamento de la organización y del pensamiento políticos de Roma" POLIS. Revista de ideas y formas políticas de la Antigüedad Clásica II, 1999, pp. 85-109.

Cicero, Marcus Tullius. (70 a. C.). In Verrem (Contra Caio Verres). Trad. José $M^{a}$ Requejo Prieto. Ed. Gredos, Madrid 1982.

D’Ors, A. (1987). La Violencia y el Orden. Madrid: Dyrsa.

D'Ors, A., Autoridad y potestad en "Escritos varios sobre el derecho en crisis", C.S.I.C, Roma- Madrid 1973, pp. 93-104.

Dri, Rubén R. (2000) "La filosofía del Estado ético. La concepción hegeliana del Estado". En Atilio A. Boron "La filosofía política moderna. De Hobbes a Marx". Ed. CLACSO, Consejo Latinoamericano de Ciencias Sociales, Ciudad Autónoma de Buenos Aires, Argentina.

Estrada, Juan Antonio. "Raíces filosóficas de la increencia: De Descartes a la modernidad”. En Razón y Fe. Págs. 305-324. Tomo 222, No1.105- noviembre 1990.

Furedi, Frank. (2013) Authority: A Sociological History, Cambridge University Press.

García Cue, J. R., "Teoría de la ley y de la soberanía popular en el "Defensor pacis" de Marsilio de Padua», Revista de Estudios Políticos, 43 (1985), pp. 107-148. 
Hegel, G.W. (1807), Fenomenología del espiritu (traducción de Wenceslao Roces y Ricardo Guerra). México, Fondo de Cultura Económica, 1966. 1. a edición en español, Madrid, 1966, pág. 107. Además, hay una edición bilingüe, con traducción y notas de Antonio Gómez Ramos, en Abada editores / UAM, Madrid, 2010, pág. 245. Versión original en alemán: G.W.F. Hegel (1807), Phänomenologie des Geistes, en Gesammelte Werke, Hamburgo, Felix Meiner, 1980.

Herrero, Monserrat. Capítulo II: "El poder político del lenguaje" en "Democracia: ¿Conceso o conflicto?". Aginismo y teoría deliberativa den la política contemporánea. Coord. Javier Franzé. Ed. Catarata. Madrid 2014. Págs. 42-62.

Locke, John. Capítulo V: "De la propiedad”. págs. 55-75. en "Segundo Tratado sobre el gobierno civil”. Trad. De Carlos Mellizo. Ed. Alianza., Madrid, 2012.

Malamud, Carlos. "Populismos latinoamericanos. Los tópicos de ayer, hoy y siempre”. Ediciones Nobel, Oviedo 2010

Márquez, Esther (2015) “La paradoja de la modernidad”. pág. 112. Tesis doctoral Universidad del País Vasco.

Mártínez, Francisco José: "Pensar hoy: Una ontología del presente". Amargord Ediciones, Colmenar Viejo (Madrid), 2015, 335p.

McIlwain, C. H. (1932) «The Growth of Political Thought in the West», New York, Macmillan, p. 313.

Mayz-Vallenilla, E. (1999). "El dominio de poder". Puerto Rico: De la Universidad de Puerto Rico, $2^{\mathrm{a}}$ ed.

Padua, Marsilio. ([1324] 1999) “Defensor Pacis”. Trad. Luís Martínez Gómez. "El Defensor de la paz". Ed. Técnos, Madrid.

Revault d'Allonnes, M. (2006). "Le pouvoir des commencements. Essai sur l'autorité". París: Éditions du Seuil. Traducción Estela Consigli "El poder de los comienzos". Buenos Aires: Amorrortu. 2008.

Roche, P., "La "plenitudo potestatis" en el "Defensor minor" de Marsilio de Padua», en Éndoxa, 6 (1995), UNED, Madrid, pp. 241-262.

Roche, $\mathrm{P}$ «La ley en el "Defensor minor" de Marsilio de Padua», Revista Española de Filosofía Medieval, 2 (1995a), pp. 91-99.

Rorty, Richard "Forjar nuestro pais. El pensamiento de izquierdas en los Estados Unidos del Siglo XX”. Ed. Paidós, 1989 Madrid

Royo Arpón, José María. (1997). “Palabras con poder”. Ed. Marcial Pons, Madrid. 
Streahel, Edgar. "Algunas claves para una relectura de la autoridad" en Las Torres de Lucca, no 7 Julio -Diciembre 2015: 171-207.http://www.lastorresdelucca. org/index.php/ojs/article/view/76/68

Tavoillot, Pierre-Henri, Qui doit gouverner?: une briève histoire de l'autorité, París, Grasset, 2011

Vanney, María Alejandra. (2009). "Potestas, Auctoritas y Estado Moderno. Apuntes sobre el pensamiento político de Alvaro D'Ors". Instituto Empresa y Humanismo. 2000. núm. 109.

Watt, J. A., «Spiritual and temporal powers», en Burns, J. H. (ed.), The Cambridge History of Medieval Political Thought, c.350-c.1450, Cambridge University press, 1991, pág. 411.

Zanatta, Loris. "El populismo" Ed. Katz, Argentina 2015.

DOI: https://doi.org/10.15366/bp.2020.24.017

Bajo Palabra. II Época. No 24. Pgs: 337-358 
